\title{
Adaptação/apagamento: Reflexões e provocações sobre a língua brasileira de sinais
}

\author{
Fábio Rodrigues dos Santos (UFAL)* \\ https://orcid.org/0000-0002-2590-3586 \\ Carlos Alberto Matias de Oliveira (UFAL)** \\ https://orcid. org/0000-0003-2283-587X
}

Sérgio Ifa (UFAL)***

https://orcid. org/0000-0002-6586-0154

\section{Resumo:}

Este artigo propõe problematizar e incitar professores e formadores de professores de Libras e de outras línguas (maternas ou estrangeiras) um (re)pensar acerca dos sentidos construídos e veiculados pelos discursos de adaptação teórica-metodológica-analítica e adaptação curricular no que diz respeito aos contextos educacionais que envolvem pessoas surdas. Com base nessa discussão, indagamos se teorizações baseadas em premissas descritivistas e analíticas de línguas orais, bem como seus respectivos processos metodológicos, contemplariam às especificidades das línguas gestuais, no nosso caso, da Libras ou se, por outro lado, não incorreriam num movimento de apagamento de tais singularidades. Assentados num posicionamento ético-político, e de acordo com as reflexões construídas neste artigo, entendemos que tais movimentos de adaptação parecem negligenciar as necessidades e interesses da população surda e, por conseguinte, assumir formas de apagamento das particularidades desses cidadãos. Adaptar refrata sentido de apagar que, por sua vez, age como força mantenedora das formas hegemônicas vigentes. Percebemos que o sujeito surdo não é visto a partir de suas realidades, pois que processos de ensino-aprendizagem e pesquisas que o envolve são naturalizados, tendo como referente o ouvinte. Logo, esse último também lhe é por parâmetro normatizador linguístico costurado

* Mestre e Doutorando em Linguística pelo Programa de Pós-Graduação em Linguística e Literatura da Universidade Federal de Alagoas. Professor no Curso de Letras da Faculdade de Letras da Universidade Federal de Alagoas. E-mail: fabio.santos@fale.ufal.br

** Mestre em Linguística pelo Programa de Pós-graduação em Linguística e Literatura da Universidade Federal de Alagoas. Tradutor e Intérprete de Libras e Língua Portuguesa da Universidade Federal de Alagoas. E-mail: carlos.oliveira@fale.ufal.br

*** Doutor em Linguística Aplicada e Estudos da Linguagem pela Pontifícia Universidade Católica de São Paulo. Professor associado no curso de Letras-Inglês da Faculdade de Letras da Universidade Federal de Alagoas. E-mail: sergio@fale.ufal.br 
pela estrutura social cisheteropatriarcal, branca e cristão de nosso contexto nacional. 0 texto finaliza com um convite à reflexão, à reconceitualização e à ação.

Palavras-chave: Discurso; Adaptação/apagamento; Pessoas surdas; Ensino -aprendizagem; Libras.

\section{Abstract:}

\section{Adaptation/erasure: Reflections and provocations about the brazilian signs language}

This paper proposes to problematize and encourage teachers and teacher trainers in Libras and other languages (mother or foreign) to (re)think about the meanings constructed and conveyed by the discourses of theoretical-methodological-analytical adaptation and curricular adaptation with regard to educational contexts involving deaf people. Based on this discussion, we asked if theories based on descriptive and analytical premises of oral languages, as well as their respective methodological processes, would contemplate the specificities of sign languages, in our case, Libras or if, on the other hand, they would not incur a movement of erasure of such singularities. Based on an ethical-political stance, and according to the reflections built in this paper, we understand that such adaptation movements seem to neglect the needs and interests of the deaf population and, therefore, assume ways of erasing the particularities of these citizens. Adapting refracts the meaning of erasing which, in turn, acts as a maintaining force of the prevailing hegemonic forms. We realize that the deaf subject is not seen from his realities, since the teaching-learning processes and research that involves him are naturalized, having the listener as a reference. Therefore, the latter is also a linguistic normative parameter sewn by the cisheteropatriarcal, white and Christian social structure of our national context. The text ends with an invitation to reflection, reconceptualization and action.

Keywords: Discourse; Adaptation/erasure; Deaf people; Teaching-learning; Libras.

\section{Introdução}

Pensar em uma sociedade que normatiza a sexualidade, a cor e a classe social, talvez não seja laborioso nos dias de hoje ante uma crescente circulação da informação e uma possível ampliação de discussões (incipientes ou não) em torno das relações sociais de forma geral. Provavelmente de igual brandura, seja pensar a partir de uma sexualidade na qual as pessoas devam se constituir, a partir de uma cor na qual ideários de beleza e capacidade devam ser prestigiados, bem como a partir do estrato social devemos esperar as produções artísticas e as produções científicas. Nesse contexto, qual é o lugar reservado à pessoa que não exibe ou possui características do espectro cishetero-branco-classe média/alta e não-patológico? É possível pensar a partir desse outro, ou ainda, é possível pensar em processos de adaptações à sociedade padrão com o intui- 
to de reparar o que entendemos ser um desequilíbrio social? Discorremos, no decorrer deste texto, essas questões centrais que nortearam e norteiam as discussões acerca do grupo socialmente marginalizado, foco deste trabalho: as pessoas com surdez.

É inegável o avanço social que a comunidade surda espalhada no Brasil teve nos últimos anos, principalmente, no que concerne aos aspectos educacionais (SANTOS, 2017): ampliação do número de pessoas surdas frequentando as escolas, mais profissionais Tradutores e Intérpretes de Libras -Português atuando em salas de aula inclusivas, (maior) acesso a cursos de graduação e pós-graduação - em instituições de ensino superior públicas e privadas - do país e, por conseguinte, maior número de pesquisas acadêmicas relativas às línguas de sinais (LSs). Contudo, como ampliação de nosso segundo questionamento acima, indagamos se esse avanço social tem se alicerçado, e assim sido analisado, pelo prisma da adaptação, ajuste, adequação, encaixe, integração, conversão (e tantos outros correlatos pertinentes) da pessoa surda a realidades majoritária e rigidamente compreendidas como ouvintes e excludentes, no que concerne ao pensar, falar e ser.

Assim, neste artigo, tencionamos promover reflexões e provocações acerca dos efeitos de sentidos (re)produzidos no/com/ através do discurso da adaptação no campo da Libras e, por conseguinte, das pessoas com surdez. Na busca desse intento, situamos este trabalho no campo da Linguística Aplicada, por compreendermos ser inescapável a relação entre língua e vida em sociedade, assentada, sobretudo, em uma agenda ético-política. Mais ainda,

Como lingüistas aplicados, estamos envolvidos com linguagem e educação, uma confluência de dois dos aspectos mais essencial- mente políticos da vida. Na minha visão, as sociedades são desigualmente estruturadas e são dominadas por culturas e ideologias hegemônicas que limitam as possibilidades de refletirmos sobre o mundo e, conseqüentemente, sobre as possibilidades de mudarmos esse mundo. Também estou convencido de que a aprendizagem de línguas está intimamente ligada tanto à manutenção dessas iniquidades quanto às condições que possibilitam mudá-las. Assim, é dever da Linguística Aplicada examinar a base ideológica do conhecimento que produzimos (PENNYCOOK, 1998, p. 24).

Portanto, nosso compromisso social diante das desigualdades sociais que podem se apresentar na aprendizagem de línguas e em outras atividades relacionadas ao ensino delas merece destaque neste artigo. Ressaltamos ainda, que não temos a pretensão de exaurir as discussões aqui construídas e nutridas, pelo contrário, a proposição é assumida e propositadamente instigadora. A isso nos propomos, considerando a urgência fazer soerguer reflexões geradoras e abertas a mais outras reflexões que partam de um sujeito não-convertido, não-encaixado e, por conseguinte, de uma Libras não-amoldada e conformada. Nesse sentido, organizamos este manuscrito para discorrer primeiramente sobre o discurso da adaptação tendo como foco os aspectos teóricos, metodológicos e analíticos em pesquisas envolvendo a Libras. Em seguida, problematizamos o discurso da adaptação no currículo escolar, no qual enfatizamos a necessidade de compreender a realidade curricular como ampliação de apenas aspectos conteudistas de currículo.

\section{O discurso da adaptação teórico- metodológico-analítica}

O campo da Linguística Descritiva (doravante LD) tem recebido uma quantidade subs- 
tancial de pesquisadores, realizando investigações de descrição e análise linguística das LSs cujos eixos centrais parecem realizar esse movimento de descrição linguística cativo a uma espécie de equiparação ad aeternum aos elementos, as categorias e a óptica analítica das línguas orais (LOs). Diante dessa realidade quase que massiva das pesquisas acerca de línguas gestuais, ampliamos as questões fundamentais deste texto, indagando a quem responde esse movimento intenso lotado (hegemonicamente) no campo da LD.

Essa percepção é motivada pelo que pensamos ser o paradoxo adaptação/autonomia, equivalente ao paradoxo aceite/abjeção. Primeiramente, é importante considerar que, para fins de reconhecimento como língua, os estudos acerca das $\mathrm{LSs}^{1}$ foram ancorados em uma base que se propunha elencar características de distinção entre línguas e sistemas de comunicação animal, a saber: flexibilidade e versatilidade, arbitrariedade, descontinuidade, criatividade/produtividade, dupla articulação, padrão e dependência estrutural, como apresentam Quadros e Karnopp (2004), quando afirmam que:

[A]lgumas definições anteriores abordadas restringiram o estudo das línguas naturais ao estudo das línguas faladas. No entanto, cabe salientar que a partir do início das pesquisas linguísticas nas línguas de sinais em torno dos anos 1960 (Stokoe, 1960; Stokoe et al. 1965), observou-se que o entendimento sobre as línguas em geral e sobre as línguas de modalidade visoespacial (sic) aumentou consideravelmente. Hoje há uma quantidade razoável de investigação na área da linguística, não apenas sobre a estrutura,

10 acesso a estudos relativos a línguas que não fazem parte do eixo euro-norte-americano não é tão fácil. Entendemos que isso seja uma forma de apagamento que faz parte do que Ramon Grosfoguel (2006) chama de "epistemicídio" resultante do constructo Modernidade/Colonialidade. mas também sobre a aquisição, o uso e o funcionamento dessas línguas (QUADROS; KARNOPP, 2004, p. 29, grifo nosso).

Contudo, pensamos que, assombrados constantemente pela dicotomia primária, linguagem humana versus comunicação animal, as investigações alçadas sobre as LSs parecem receosas em se distanciar de quaisquer trajetos outrora não trilhados pelas LOs, sob o risco da rejeição. Quase duas décadas após a afirmativa de Quadros e Karnopp (2004), citada acima, mais do que nunca é possível atestar que "há uma quantidade razoável de investigação na área da linguística", todavia, inquieta-nos pensar que essas pesquisas sobre as LSs se mantenham cativas ao parâmetros de análise e compreensão das LOs, ainda que com o objetivo de fazer uma adaptação e não o de fazer uma verdadeira tradução desse conhecimento junto às realidades de línguas gestuais.

Diante disso e, mais uma vez desdobrando os questionamentos centrais deste texto, lançamos suspeitas acerca dessa pressuposta adaptação: será que isso, na verdade, não estaria, relegando os estudos acerca das LSs, no nosso caso mais específico, da língua brasileira de sinais - Libras, às sombras da subserviência linguística ante os sentidos que adaptar tem assumido no âmbito educacional de pessoas surdas? Insistimos num olhar para o outro que vá além dos limites da adequação investigativa, ou melhor, que rompa com a égide de pesquisas ajustadas a uma língua totalmente diversa, a começar por sua modalidade de materialidade, gestual. Além do mais, compreendemos que essas investidas tendem a lançar mão de um amoldamento, encaixe e justaposição do próprio sujeito surdo a realidades que não lhes dizem nada ou dizem pouco e que favorecem ao apagamento de suas possíveis múltiplas e diversas existências. 
Ao se referir às pesquisas em aquisição ${ }^{2}$ de segunda língua ${ }^{3}$ (ASL) no contexto de sala de aula, Pennycook (1998) diz que:

por meio de medidas quantitativas das relações de causa e efeito, em situações quasi-experimentais, tem tratado a sala de aula como um lugar de meras trocas linguísticas, em vez de buscar entendê-la como um local complexo de interação social. A produção científica exploradora das dinâmicas sociais, culturais e políticas das salas de aula de segunda língua tem sido irrisória (PENNYCOOK, 1998, 33, grifo do autor).

Nas discussões relativas à Libras no âmbito educacional, entendemos e priorizamos a relação entre o contexto escolar e a sociedade ao não desassociar as relações possíveis entre ambos os contextos. Embora saibamos que a língua a qual Pennycook faz referência nesse contexto de ASL - o inglês - possua uma relação com mundo díspar do que Libras possui, o movimento teórico-paradigmático e metodológico parece seguir as mesmas veredas: uma cosmovisão euronorte-americana, positivista e, neste caso, com o acréscimo do foco no aspecto fonocêntrico.

Substanciando nosso feixe de raciocínio, temos que o nascedouro das pesquisas acerca das LSs se constitui aninhado em descrições linguísticas no que diz respeito aos traços distintivos, aos estudos lexicais e, principalmente, ao estudo da sintaxe, a partir do pesquisador norte-americano Stokoe, em 1960 (QUADROS; KARNOPP, 2004). Por

2 Embora tenhamos preferência pelo termo "aprendizagem" em detrimento de "aquisição", utilizaremos neste texto o vocábulo apresentado pelo autor referenciado.

3 Apesar de reconhecermos que há distinção entre segunda língua e língua estrangeira, neste texto, porém, não a faremos, pois o foco central da discussão é, como diz Pennycook, ter o foco central das discussões em pesquisas na complexidade da interação social e suas implicações sociais, culturais e políticas. conseguinte, os estudos sobre Libras parecem se vencilhar a esse prisma positivista de fazer ciência em Linguística e, atrelado a isso, há o diapasão da investigação linguística baseada em línguas fonoarticulatórias que, desconfiamos nós, nem sempre (ou quase nunca) serve de padrão para a afinação. Por outro lado,

[I]sso não seria um problema tão sério, caso a pesquisa norte-americana, com sua tendência universalizante de modernidade, aliada ao apoio das universidades de prestígio e de suposto rigor do método positivista, não estivesse exportando suas descobertas como uma forma de verdade universal para o resto do mundo (PENNYCOOK, 1998, p. 33).

Embora haja, por parte da comunidade científica, o entendimento de que "[A] língua de sinais tem estrutura própria, e é autônoma, ou seja, independente de qualquer língua oral em sua concepção linguística" (GESSER, 2009, p. 33), parece haver também uma recorrência de textos da área buscando ratificar esse selo de língua. É como se esse atestado de língua legítima fosse tão tênue que precisasse ser validado com certa regularidade e, além disso, esse status de língua só seria alcançado através de pesquisas centradas na descrição linguística e análise do funcionamento fono-morfo-sintático. Sendo assim, essa é a resposta dada ao campo que detém hegemonia na quantidade de pesquisas em LSs, pois que, não diferentemente, até mesmo em ares de aquisição, as pesquisas em LSs ainda estariam inegavelmente sequestradas pela análise de seus respectivos arranjos fono-morfo-sintáticos.

Cabe ressaltar, que compreendemos que a excessiva preocupação em reafirmar a Libras enquanto língua (fato já oficializado há mais de $15 \operatorname{anos}^{4}$ ), decorre do descompasso

4 Por meio da Lei Federal № 10. 436 (BRASIL, 2002). 
existente entre o texto legal e a realidade social. $\mathrm{O}$ aparato legal não foi suficiente para deslocar a Libras e seus falantes dos lugares periféricos e marginalizados aos quais sempre foram historicamente delegados. Ante a isso, tem-se recorrido ao campo acadêmico como caminho e instrumento para preencher esse hiato e consolidar a Libras enquanto língua (legitimada). Possuindo prestígio sócio-científico, o campo acadêmico tem recebido diversos pesquisadores determinados a (provar) equiparar a Libras às línguas vocalizadas, no intuito de elevá-la ao mesmo nível de prestígio social das línguas hegemônicas.

Todavia, os investimentos de equiparação/adequação acabam por moldar a Libras aos padrões fonocêntricos, apagando, por consequência, as especificidades, as características singulares dessa língua gestual, cujas propriedades não são iguais às LOs. Ao invés da busca por autonomia, recorrese a fazer adaptação, ao que nos parece uma subserviência linguística para que haja aceite dos outrora abjetados. Indo na contramão, subscrevemo-nos a importância de destacar que, são as especificidades, as singularidades da Libras em uso é que ela se difere de uma língua fonoarticulatória. São nessas particularidades que reside a beleza das línguas de sinais. É no olhar a partir das singularidades que reside e pode germinar outras epistemes, saberes que melhor dizem das pessoas cujo principal meio de interação é o gestovisual. E, por assim dizer, essa singularidade linguístico-cultural da Libras, propiciadora das práticas discursivas construtoras de realidades sociais (MOITA LOPES, 2002), não podem, nem devem, ser tomadas como menos língua e/ou socialmente inferior, refletindo o que chamamos de desequilíbrio social.

Desse modo, a frequência desse movimento unilateral de equiparação das LSs às
LOs contido em processos de adaptação, motivo pelos qual os tomamos por equivalentes neste trabalho, age, na nossa compreensão, no sentido de acorrentar ainda mais a Libras às línguas vocal-auditivas. Ao invés de se configurar como atos de resistência e de afirmação das línguas de sinais, esse movimento de equiparação/adaptação e, como consequência, de apagamento constitui uma rede discursiva que retroalimenta e reforça a soberania das LOs, assim como ratifica a ideia de hierarquia (em quaisquer níveis) entre ouvintes e surdos, tendo em vista que decorre "de uma estrutura de opressão que privilegia certos grupos em detrimento de outros" (RIBEIRO, 2019, p. 31).

Outrossim, entendemos que esse movimento unilateral apresenta-se como uma empreitada por aceitação da hegemonia ouvinte, um modo de obter um passe para habitar a ilustríssima torre de marfim, acreditando, pelo que parece, obter uma ilusória carta de alforria e, dessa maneira, livrar-se dos olhares preconceituosos e marginais que cerceiam as consideradas não-línguas e seus falantes. Em outras palavras, obter o tão almejado selo de língua. No entanto, longe de se tornarem libertas, o equiparar/ adaptar/apagar implica, analogicamente, no "condicionamento de um povo a aceitar o que o colonizador, detentor do poder, impuser" (SIQUEIRA, 2014, p. 74), ou, como nos diz Bourdieu (2001, p. 11), na "domesticação dos dominados". A hegemonia ouvinte, ideologicamente orientada, torna a língua vocalizada um espelho para as LSs, a partir do qual estas últimas lhe devem ser por reflexo, mesmo que quase sempre isso não seja possível.

Isso posto, como circunscrito no objetivo deste artigo, tencionamos provocar reflexões para que seja possível quebrar quaisquer correntes de subjugação teórico-meto- 
dológico-analítica que, porventura, produza línguas-subjugadas e, ante a indissociabilidade sujeito-língua, sujeitos-subjugados. Desse modo, combatemos o que entendemos ser uma violência linguística que ainda assola as LSs e o surdo, o apagamento. Em outras palavras, defendemos que a Libras seja vista e investigada não como um subproduto das LOs, mas de forma realmente independente, ainda que dispute/compartilhe com uma delas - a língua portuguesa - mesmo espaço-tempo. Defendemos que é preciso falar da Libras a partir da Libras, discutir sobre surdez a partir das pessoas surdas, num movimento autônomo, livre e libertador. Corroboramos com o posicionamento de que é preciso falar não apenas a respeito da periferia, mas a partir da periferia (KLEIMAN, 2013, p. 46), considerando a periferização, a marginalidade vivenciada tanto pelas pessoas surdas quanto pelas pesquisas que envolvam (de alguma forma) essa demanda social.

Por fim, somos do entendimento de que para mudar essa realidade de dominação e subalternização, esquivando-nos de quaisquer formas de eufemismo, é necessário que os grupos minoritarizados tomem a dianteira de suas próprias narrativas, de sua própria história e de suas pesquisas ${ }^{5}$. 0 estado de dominação não é irreversível, “o colonizado deve ser capaz de escolher entre a passividade e a não aceitação, deve ser capaz de decidir por si mesmo se deseja lutar ou se deseja continuar a ser diminuído pelo colonizador" (SIQUEIRA, 2014, p. 75).

5 Não há nesta afirmativa nenhuma pretensa exclusividade investigativa, contudo, entendemos a urgência de se reclamar espaços de coparticipação dos saberes de pessoas e línguas inferiorizadas, subalternizadas e, por conseguinte, marginalizadas, uma vez que isso reflete e refrata em suas existências (e vice-versa).

\section{O discurso da adaptação curricular}

O discurso da adaptação tem campeado e produzido efeitos de sentido em diversos vieses do contexto educacional, sobretudo, nas discussões que envolvem uma compreensão curricular mais ampla, queremos dizer, desde discussões acerca da matriz curricular as de ações e materiais didático-pedagógicos desenvolvidos em salas de aula inclusivas. Nessa conjuntura, pautados numa orientação supostamente inclusiva, o termo adaptação surge como solução para as barreiras de exclusão e segregação que, premente, ainda constituem os espaços de sala de aula, considerando que, de acordo com Mesquita et al (2018, p. 70), o "movimento da inclusão trouxe e colocou em destaque a ideia de adaptar, flexibilizar, adequar" currículos, metodologias e avaliações. $\mathrm{E}$, no que concerne mais especificamente ao ensino de pessoas com surdez, não raro, observarmos discursos que defendem a adaptação como instrumento de excelência para o ensino desse alunado.

Destarte, baseados nessa premissa de adaptação como solução, diversos materiais da literatura têm sido adaptados para comunidade surda, principalmente da literatura infantil, por exemplo: Cinderela, para Cinderela Surda; Rapunzel, para Rapunzel Surda, entre outros títulos ajustados à Libras. Semelhantemente, essa conversão se estende, praticamente, às demais realidades de sala inclusiva, quer na pura conversão de materiais didáticos da língua portuguesa escrita para Libras, quer nos ajustes metodológicos para o ensino do alunado surdo ou em algumas adaptações na matriz curricular.

Contudo, no mesmo espírito inquiridor que erigiu o tópico anterior, indagamos acerca do efeito de sentido solucionista re- 
fratado através do discurso, (re)produzido no contexto educacional, de adaptação curricular voltado para às pessoas com surdez. Para refletirmos sobre isso, partirmos do entendimento de que a adaptação literária, em rumo de distanciamento de um pensar a partir do outro, tem por tendência duas facetas: folclorizar a adaptação e negligenciar as possibilidades textuais da comunidade surda.

Para a primeira faceta, a adequação tende a ser tomada como uma forma de manifestação puramente artística devido a língua que a veicula. Libras parece ser reconhecida como uma espécie de folclore, num possível sentido pejorativo do termo, pois que mesmo fazendo parte da sociedade mais ampla, restringe-se a um grupo específico que, vez por outra, faz-se visível e tem sua beleza e diferença admirada pela grupo social majoritário. Como efeito dessa primeira, visualizamos a segunda faceta, a da negligência. Para nós, esse movimento de adaptação tende a ludibriar quaisquer significados de acesso sócio-político e cultural desse outro com o qual dialoga e configura sentido de indiferença em relação às suas produções textuais autônomas. Logo, produções que dizem da realidade material de sua linguística, bem como das realidades construídas a partir dessa linguística são, como resultado da adequação solucionista, apagadas.

Não diferentemente, concebemos também que a conversão de materiais didáticos, os ajustes metodológicos para o ensino e a adaptação da matriz curricular parecem desconsiderar as construções político -identitárias que a Libras desenvolve com/ na/pela pessoa surda, bem como nas relações que essas pessoas estabelecem com os não surdos. Esperamos estar explícita que a problemática circunscrita em torno da adaptação não diz respeito especificamen- te a esse tipo de ação, mas aos sentidos que ela vem assumindo nos contextos relativos à vida das pessoas surdas e, neste artigo, aos contextos educacionais dos quais elas participam.

Nesse sentido, é imprescindível atentar para os sentidos refletidos e refratados pelas palavras que constituem nosso discurso ([re]produzido), uma vez que nelas "se realizam todos os fios ideológicos que penetram todas as áreas da comunicação social" (VOLÓCHINOV, 2017, p. 106). Fazemos esse destaque, ante a compreensão de que tais fios ideológicos constroem e são construídos por nossos discursos e, atuando na capilarização social, orientam e balizam, por sua vez, as relações entre os sujeitos. A partir disso, consideramos que o termo "adaptar" não é esvaziado de intencionalidade, mas recupera e dá continuidade à direções de sentidos que afetam as realidades das denominadas práticas inclusivas, sendo-lhe, na ocasião desta discussão, por promessa solucionista.

Em contrapartida, convém igualmente atentar que esse adaptar pressupõe um precedente, um ponto de partida de onde emerge o padrão, o modelo, a referência que servirá de base para parciais (ou pequenas) modificações cumpridoras da adaptação, adequação, ajuste, entre outros correlatos. Por esse prisma, adaptar algo não implica necessariamente numa mudança de paradigmas, mas em superficiais arranjos que ainda preservam, inevitavelmente, a essência do referente e de seus interesses, diante de um discernimento político-sócio-histórico e não-neutro.

Portanto, o discurso pró-adaptação/ adequação é ideologicamente orientado e parece estar a serviço da manutenção de interesses hegemônicos, isto é, dos não-patológicos para preservar as bases estruturais 
de poder que esses exercem sobre os patologicizados. Esse discurso, que transpassa todos os setores da sociedade, inclusive os contextos educacionais, produz uma falsa impressão de inclusão, velando currículos pré-estabelecidos, pré-formados, fixos, estanques, engessados e blindados a qualquer forma de real alteração, movidos, sobretudo, por um projeto de manutenção do status quo, o de exclusão do surdo.

O discurso da adaptação tem sido naturalizado e ganhado palco, sendo ovacionado como a resolução de todos os entraves no ensino para pessoas com deficiências por propiciar uma (pseudo) equidade. É um discurso que seduz, que requer estabilidade e que produz uma cênica percepção de igualdade, de equilíbrio social, pois que os processos de adequação didático-pedagógicos e curriculares estariam dando acessibilidade educacional aos marginalizados. Assim, envolvidos nessa corrente discursiva, muitos profissionais e pesquisadores da área da surdez têm, conscientes ou não, reproduzido esse discurso que funciona como força motriz, refratadamente, de dominação e manutenção das desigualdades.

Esse discurso, assim como o de adaptação para fins investigativos discutido no tópico anterior, também age em via de unilateralidade: o grupo hegemônico nunca está aberto a adaptações para com o surdo; somente esse diferente é que precisa se amoldar para caber no espaço que é da maioria ouvinte, tendo em vista que o contexto educacional não é, aparentemente, um espaço comum - compartilhado. Os alunos diferentes necessitam se encaixar nos moldes reguladores, discursivamente construídos, sob o risco de exclusão, caso queriam partilhar dos contextos educacionais e dos saberes produzidos nesses espaços recém conquistados.
Nesse sentido, em tais espaços de hegemonia ouvinte, percebemos uma urdida lógica atuando na construção e execução de currículos, metodologias e avaliações que tomam o ouvinte como a gênese e referente, exigindo do surdo empenho para se enquadrar em padrões ouvintes, isto é, para ir além de sua realidade linguística, cultural e até física (na maioria dos $\operatorname{casos}^{6}$ ). Essa exigência de um para além de suas existências, o que nos parece desumano, marca ainda mais esse lugar de outro que o surdo ocupa, pois que "o status de ser o 'outro' implica ser o outro em relação a algo ou ser diferente da norma pressuposta", como bem destaca Collins (2016, p. 5, grifo do autor) ao tratar do racismo. Logo, temos um outro fora da norma social e, muitas vezes, da academia, mas que sob a folclorização e apagamento da adaptação é pseudo-incluído.

\section{Considerações não-finais}

As reflexões substanciadas neste artigo visam pensar na democratização do acesso ao conhecimento por meio de investigações e realidade curricular que tomem as especificidades das pessoas surdas como ponto de partida, para, desse modo, atingir processos de ensino-aprendizagem realmente inclusivos. Isso em vista, partindo propositadamente primeiro, para fins contextuais, das discussões que fizemos sobre adaptação na matriz curricular, em materiais didáticos, literários e metodológicos para as pessoas surdas, reflexionamos que tal realidade tem sido desenhada a partir de modelos ouvintes, reproduzindo "o saber de um grupo do-

6 Considerando que a maioria das pessoas surdas possui perda auditiva significativa o suficiente para inviabilizar processos de interação verbal via circunstâncias oro-auditivas - ainda que surdos oralizados lancem mão, necessariamente, de elementos outros para essa forma de comunicação, a leitura orofacial, por exemplo. 
minante que manipula o conhecimento e os saberes com base na afirmação de uma hegemonia racional que coloca em desvantagem as minorias desprivilegiadas dos bens culturais" (ONOFRE, 2008, p. 106).

Já no que diz respeito ao que chamamos de subserviência linguística, pensamos que a mesma moldagem que recai sobre a pessoa surda e torna os espaços educativos um não-lugar desse outro, no qual ele precisa se encaixar, é utilizada como prisma para as investigações da língua gestual por meio da qual essas pessoas interagem no mundo e com o mundo. Receosos aos assombros do fantasma da ilegitimidade das LSs, no nosso caso, da Libras, as pesquisas relativas à essa língua se mantêm prisioneiras a uma cosmovisão euro-norte-americana, positivista e fonocêntrica em seus processos teóricometodológico-analítico.

Assim, para além da adaptação curricular, metodológica e - ainda que não discutida, mas inevitavelmente presente nesse âmbito educacional - avaliativa, as investigações acadêmicas cujo objetivo é a Libras, também continuam, infelizmente, não ouvindo as pessoas surdas. A famigerada adaptação tem provocado apenas certo encantamento e uma ilusória sensação de equidade e justiça social que pode ser facilmente comprada e difundida por muitos profissionais e pesquisadores da área.

Diante disso, frisamos nosso posicionamento em reclamar uma reflexão acerca dos efeitos de sentido engendrados com/no/ através do discurso da adaptação, mesmo que isso implique em possíveis desconfortos para alguns dos tais profissionais e pesquisadores. Compreendemos a possibilidade de negação, ou não-aceitação dos apontamentos aqui levantados visto que "ideias e verdades desagradáveis seriam mantidas fora da consciência por conta da extrema ansiedade, culpa e vergonha que elas causam" (RIBEIRO, 2019, p. 79). Entendemos ainda que a negação ou desconforto causado aconteça porque, talvez, sempre estivemos acostumados a ouvir nossas próprias vozes. Todavia, mesmo diante da possibilidade de desagrado, somos movidos por um compromisso ético-político, de reconhecimento de nossa responsibilidade ${ }^{7}$ (SOBRAL, 2016) na desconstrução de práticas discursivas opressoras de silenciamento e apagamento. Apagamento que, segundo consideramos, vem mascarado de equiparação, adaptação e/ou ajuste.

\section{Referências}

BOURDIEU, P. 0 Poder Simbólico. Trad. Fernando Tomaz. 15 ed. Rio de Janeiro: Bertand Brasil, 2001.

BRASIL, Lei no 10.436, de 24 de abril de 2002, que dispõe sobre a Língua Brasileira de Sinais - Libras e dá outras providências. Disponível em: <http://www.planalto.gov.br/ ccivil_03/LEIS/2002/L10436.htm>. Acesso em: 01 de nov. de 2019.

GESSER, A. LIBRAS?: Que língua é essa?: crenças e preconceitos em torno da língua de sinais e da realidade surda. São Paulo: Parábola Editorial, 2009.

KLEIMAN, A. B. Agenda de Pesquisa e Ação em Linguística Aplicada: problematizações. In. MOITA LOPES, L. P. (Org.). Linguística Aplicada na Modernidade Recente: festschrift para Antonieta Celani. São Paulo: Parábola Editorial, 2013, pp. 39-58.

MENDES, E. G.; TANNÚS-VALADÃO, G.; MILANESI, J. B. Atendimento Educacional Especializado para estudante com deficiência intelec-

7 Vocábulo proposto por Sobral (2016) para unir as noções de responsabilidade e responsividade abordadas por Bakhtin. Segundo o autor, o termo objetiva "designar por meio de uma palavra tanto o aspecto responsivo como o da assunção de responsabilidade do agente pelo seu ato, um responder responsável que envolve necessariamente um compromisso ético do agente" (SOBRAL, 2016, p. 20). 
tual: os diferentes discursos dos professores especializados sobre o que e como ensinar. Revista Linhas. Florianópolis, v. 17, n. 35, p. 4567, set./dez. 2016.

MESQUITA, A. M. A.; RODRIGUES, J. F. B.; CASTRO, K. P. A Política Curricular no Contexto da Inclusão e seus Mecanismos de Diferenciação Curricular. Revista Teias v. 19, n. 55, Out./ Dez. 2018. pp. 70-88.

ONOFRE, J. A. Repensando A Questão Curricular: caminho para uma educação anti-racista. Práxis Educacional, Vitória da Conquista, v. 4, n. 4, p. 103-122, jan./jun. 2008.

PENNYCOOK, A. A Linguística Aplicada dos anos 90: em defesa de uma abordagem crítica. In: SIGNORINI, I.; CAVALCANTI, M. (orgs.). Linguística Aplicada e Transdisciplinaridade. Campinas: Mercado de Letras, 1998.

QUADROS, R. M.; KARNOPP, L. B. Língua de sinais brasileira: estudos linguísticos. Porto Alegre: Artmed, 2004.

RIBEIRO, D. Lugar de fala. São Paulo: Pólen, 2019.

SACRISTÁN, J. G. Currículo e diversidade cultural. In: SILVA, T. T.; MOREIRA, A. F.(Org.). Territórios contestados: o currículo e os novos mapas políticos e culturais. Petrópolis: Vozes, 1995.

SANTOS, F. R. Um estudo sobre o processo de ensino-aprendizagem dos alunos da disciplina Libras no curso de Licenciatura em Letras-Português de uma instituição do ensino superior pública de Alagoas. 2017. 153 f. Dissertação (Mestrado em Linguística) - Universidade Federal de Alagoas, Maceió, 2017

SIQUEIRA, G. V. Q. A Relação Colonizador X Colonizado em as Aventuras de Ngunga. Revista Arredia, Dourados, MS, Editora UFGD, v.3, n.5: 62-76 ago./dez. 2014.

SOBRAL, A. Ato/atividade e evento. In. BRAIT, B.(Org.). Bakhtin: conceitos-chave. 5. ed. São Paulo: Contexto, 2016, pp. 11-36.

STREVA, J. M. Colonialidade do Ser e Corporalidade: 0 Racismo Brasileiro Por Uma Lente Descolonial. Revista Antropolítica, n. 40, Niterói, p.20-53, 1. sem. 2016.

VOLÓCHINOV, V. Marxismo e a filosofia da linguagem: problemas fundamentais do método sociológico na ciência da linguagem. Tradução, notas e glossário de Sheila Grillo e Ekaterina Vólkova Américo. São Paulo: Editora 34, [1929] 2017. 